\title{
Medisin for samfunnskroppen
}

\author{
Gjennom heile forfattarskapen har eg vore opptatt av at skarpe motsetningar - mellom høgt og lågt, fattig \\ og rik, vulgært og forfina, stygt og vakkert, godt og vondt - kan koma til uttrykk i ein og same person. På \\ samfunnsnivå toppar slike kontrastar seg i spenningsforholdet mellom barbari og sivilisasjon. Gir ein seg \\ først i kast med dette stoffet, kjem ein uavvendeleg til Det tredje riket og det store sivilisasjonssamanbrotet \\ i moderne tid. Konsentrasjonsleiren Auschwitz har sidan blitt symbolet på dette samanbrotet.
}

\section{Kjartan Fløgstad}

kjarflog@online.no

Oslo

I mai 1943 kom den unge legen Josef Mengele (1911-79) til Auschwitz i det tyskokkuperte Polen (1). Dr. Mengele var fødd i velstand i Bayern, utdanna som antropolog i München og som arvebiolog under rasehygienikaren Otmar von Verschuer (1896-1969), som var direktør for det velrenommerte instituttet for arvebiologi og rasehygiene (Institut für Erbbiologie und Rassenhygiene) i Frankfurt am Main og dommar ved Erbgesundheitsobergericht.

I Auschwitz heldt Mengele, som både var dr.med. og dr.phil., fram med samarbeidet med von Verschuer. Som Hauptsturmführer og leirlege kunne han bruka levande menneske til medisinske eksperiment og senda resultata til sin mentor i Frankfurt. For fangane blei Mengele sjølve symbolet på dei medisinske dødsenglane som sto på perrongen og skilde mellom liv i fornedring og fangenskap og brå død i gasskammeret.

\section{Oppglødde medisinarar}

Men Mengele var langt frå aleine. Sosialdarwinisme og arvebiologi sto sterkt ved tyske universitet. I langt større grad enn gjennomsnittet hadde tyske studentar og akademikarar ønskt Det tredje riket velkommen (2). Juristar og medisinarar var særleg oppglødde. Størstedelen av domstolspersonalet gjekk inn i Nationalsozialistische Deutsche Arbeiterpartei (NSDAP) eller i underavdelingar av partiet. Begge dei største legeforeningane gjekk saman med den nazistiske standsorganisasjonen for legane.

Etter kvart såg mange tyske legar det slik at etisk sett var det viktigare å hindra liding enn å berga liv når liv blei sett på som uverdige og livsudugelege. Dette gav sterke argument for eutanasi og miskunndrap. I Platons manndomsdialog Faidon kunne dei som ønskte det, finna dei første tilløp til argument for biologisering av politikken (3). I Faidon blir undersåttane sett på som ein kropp og lovgivaren som legen, den som kan lega dei politiske sjukdommane som rammar samfunnskroppen.

Også Nietzsche-teksten Moral für Ärzte gav eit filosofisk grunnlag for det etiske og humane i å eliminera «livsudugelege» menneske (4). Den startar slik: «Pasienten er ein parasitt på samfunnet. I ein viss tilstand er det uanstendig å leva vidare. $\AA$ vegetera vidare i feig avhengighet av legar og praksis, når meininga med livet, når retten til å leva er borte, burde samfunnet sjå på med djup forakt» (eigen oversetting). Og så vidare. Slagordet var «Heilen durch Töten». Med andre ord: «Lega ved å ta liv» eller «Bli frisk av å døy»!

Då den sterkt høgreorienterte vitskapsmannen Louis Pasteur (1822-95) innførte omgrepet «bakterie», skreiv han om bakterien i same ordelag som blei brukte for å skildra dei sydande, skitne folkemassane (5). Når

\section{«Samfunnskroppen måtte vernast mot smitte nedanfrå og pestberarar utanfrå»}

bakteriane i mikroskopet likna på folk i gatene, kunne omvendt massane samanliknast med bakteriar i samfunnskroppen. Hitler sjølv rosa Pasteur og samanlikna jødedommen med ein bakteriell sjukdom.

Under legeprosessen i Nürnberg etter krigen argumenterte Hitlers livlege, dr. Karl Brandt (1904-48), slik: «Vi tyske legar ser på staten som eit individ vi først og fremst skuldar truskap, og derfor nøler vi ikkje med å øydeleggja ei opphoping av, til dømes, ein billion celler i form av eit visst antall individuelle menneskelige vesen, dersom vi meiner at dei er skadelege for den totale organismen - staten - eller dersom vi føler at staten vil ha det betre utan dei» (eiga omsetting) (6). Nazistane var raske med å gjera ord til handling. Etter maktovertakinga i 1933 mista 10000 jødiske og venstreorienterte legar retten til å praktisera (7). Mange blei drepne eller drivne i eksil. Frå dei til saman 62000 attverande kollegane kom ingen protestar eller støttefråsegner. $26 \%$ av legane var med i SA, $7 \%$ blei tekne opp i SS. Opp mot halvparten av alle tyske legar melde seg inn i NSDAP. Dette talet var langt over landsgjennomsnittet og høgare enn for lærarar og juristar.

\section{Samfunnet som kropp}

Mange av dei sentrale rasistiske ideane bak nazistisk tenking skreiv seg frå legehald og gav opphavsmennene betydeleg makt. I det heile stod førestillingar om sosialhygiene sterkt i breie lag av dei herskande klassane og blei framførte på eit slags medisinskvitskapleg grunnlag også i norsk akademia (8)

I industriland som Tyskland var underklassen organisert i ein sterk og militant arbeidarklasse. Innanfor dei gamle sosiale og økonomiske elitane herska stor frykt for det som blei sett på som det sydande og irrasjonelle folkedjupet. Tanken om samfunnet som pasient vekte stor gjenklang i slike krinsar og førte til krav om at samfunnskroppen måtte vernast mot smitte nedanfrå og pestberarar utanfrå (9). I slike banar tenkte og handla mange framståande talsmenn, ikkje berre for den tyske legestanden, men for tyske akademikarar i det heile. Etter krigen underviste dei nye generasjonar tyske, og mange kommande norske legar, i spørsmål om liv og død.

Juristane gjorde på si side ein skarpsindig innsats for å forsona paragrafane i det borgarlege lovverket med statleg massemord og allmenn rettsløyse. Mange var kritiske til Den endelege løysinga (Endlösung), ikkje i og for seg, men fordi dei meinte folkemord burde gå føre seg i juridisk ulastelege former. Dette var eit av dei mest sentrale, og heftigaste diskusjonsemna under den såkalla Wannsee-konferansen, der over halvparten av deltakarane i planlegginga av Holocaust hadde akademiske doktorgrader: Bühler, Freisler, Klopfer, Lange, Leibbrandt, Meyer, Schöngarth, Stuckart (10). 


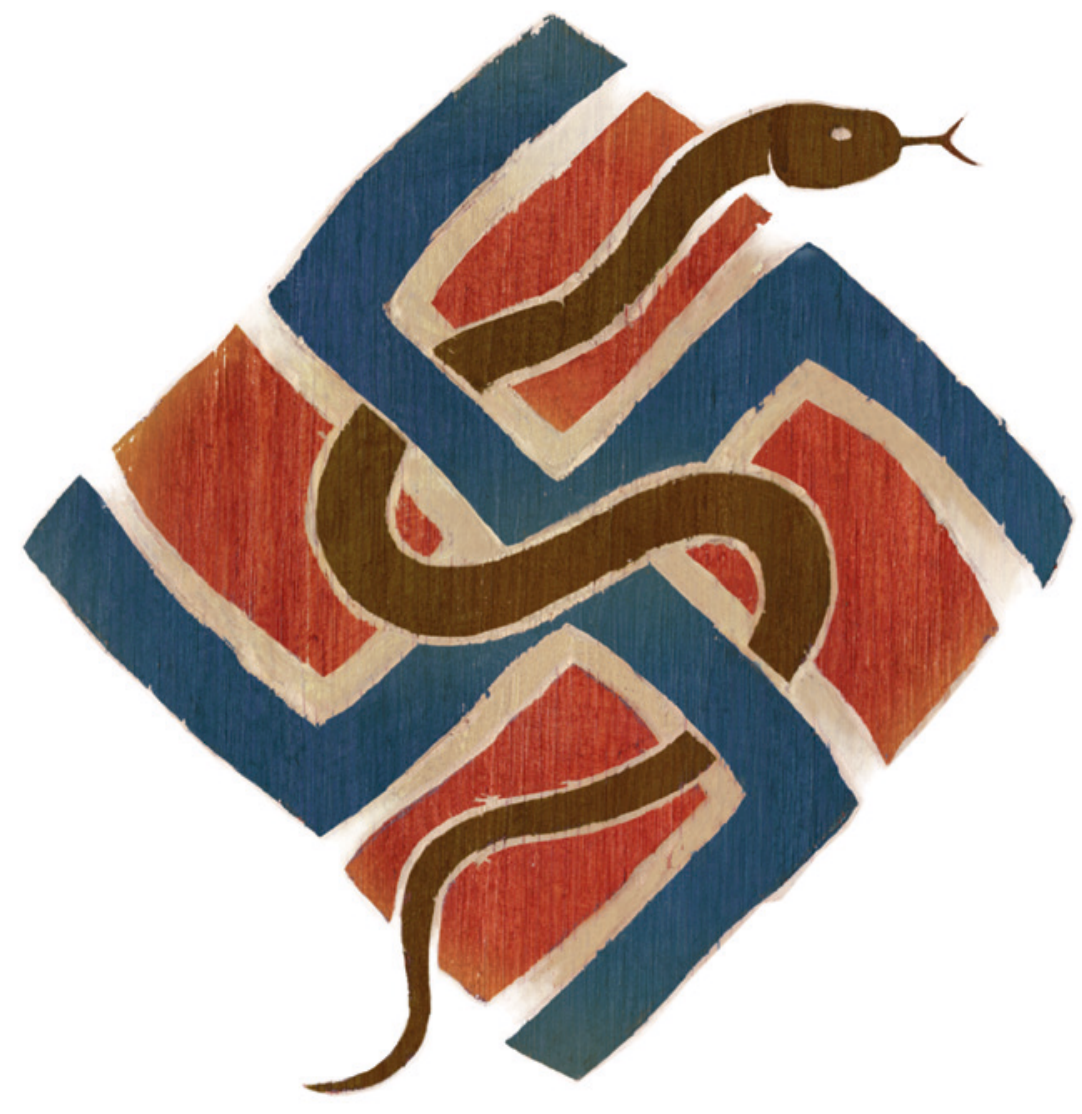

Illustrasjon $\odot$ Stein Løken

Som hand i hanske styrte særleg to grupper frå den gamle føringseliten det nazistiske samfunnsprosjektet. Med bakgrunn $i$ herskande vitskaplege førestillingar gjorde legestanden medisinske begrep om til metaforar for samfunnsforståing. Sosialhygienen kravde maktbruk mot alt som kunne truga den sunne samfunnskroppen. Blod og rett blei kopla saman. Deretter gjorde rettsvesenet dei statlege brotsverka lovlege.

Karl Larenz (1903-93), ein av dei sentrale sivilrettslege naziteoretikarane formulerte det slik: «Den som ikkje har tysk blod i årene, står utanfor folkefellesskapen, og dermed utanfor rettsstaten» (eigen oversetting) (1). Etter krigen fekk same mann den viktige lærestolen i borgarleg rett, sivilrett og rettsfilosofi i München. Pragmatisk juss rettferdiggjorde den «vitskaplege» medisinske fanatismen. Demagogien kunne overta, utforma av vennleg innstilte penneknektar og edelpennar.

På meisterleg vis klarte nazismen å mobilisera breie lag av folket, gjera dei medskuldige i og belønna dei for brotsverka til nasjonalsosialismen. Men framfor alt var den eit elitefenomen (11).

I ettertid er det flokkar av øldrikkande bøllar som har prega vårt bilde av nazistane. Endå meir skremmande er dei velutdanna, velfødde skarane av champagnemenneske frå danningsborgarskapet som var overtydde om at dei berre kunne forsvara klasseprivilegia sine med nazistane ved makta. Det handlar altså ikkje om fascisme i utmarka og i utkanten, som i Markens grøde, men om den velpleidde og kultiverte fascismen midt i hjartet av den liberale, europeiske danninga.

\section{Tyske nazilegar etter 1945}

Delinga av Tyskland etter den allierte sigeren i 1945 førte etter kvart til ein stri straum av flyktningar vestover frå den Sovjet-styrte austsonen. Mange av desse var akademikarar som frykta for framtida og levebrødet i aust. Denne opphopinga, ikkje minst av legar og advokatar, førte til ein konsentrasjon av tidlegare nazistar i Forbundsrepublikken (12). Delar av styringsverket hadde fleire gamle partimedlemmer i 1948-49 enn under Hitler. Forsiktig sagt la dette ein sterk dempar på tendensane til avnazifisering.

Nokre få legar, blant dei Karl Brandt, var dømde til døden og avretta under den allierte legeprosessen i Nürnberg like etter krigen. Etter ein kortare eller lengre karantene heldt dei fleste likevel fram som før, det galdt blant andre Josef Mengeles medisinske oppdragsgivar von Verschuer. Mange av dei norske medisinarstudentane som fekk utdanninga si i Tyskland i etterkrigstida må ha hatt lærarar med ei interessant fortid.

Josef Mengele levde lenge under jorda i heimlandet, men 20. juni 1949 gjekk han i land i Argentina med ein båt frå Genova og med pass frå den internasjonale Raudekrossen, skrive ut i namnet til Helmut Gregor (1). I Argentina var det mange Alte Kameraden frå før, også ved den tyske ambassaden. Dei var omhyggelege med kva dei såg og kva dei ikkje såg og høyrde (13). Frå 1956 kunne Mengele leva fredeleg rundt om i Sør-Amerika med namnet José Mengele i passet, i god kontakt med familien og med representantar for den store tyske kolonien, til han døydde ein naturleg død i Brasil i 1979.

\section{Nazistar blant norske legar}

Som i andre europeiske land sto tankane om sosialhygiene sterkt også i den norske styringseliten i tida fram til den andre verdskrigen (14). Dette gjeld for heile det politiske spektret. Det fekk sine mest ytterleggåande utslag i sterilisering av 44000 menneske frå sosiale utgrupper med «dårleg arvestoff» (15). I Norge blei den politiske nazismen likevel aldri ei folkerørsle. Den brutale tyske okkupasjonen var heller ingen god reklame, trass $i$ at tyskarane hadde store forhåpningar, ikkje minst til 
norske studentar, som blei internerte for å trenast opp til å bli supergermanarar (16).

Likevel var det ikkje meir enn til saman rundt 20 norske legar og medisinarstudentar som gjorde teneste som frontkjemparar på tysk side under krigen (17). Fem av desse mista livet, dei andre blei dømde for landssvik og fekk til dels lange fengselsstraffer. Av dei mest prominente nazilegane fekk Hans Eng (1907-95) lov til å praktisera vidare etter soning, i eit slags indre eksil i Kvænangen i Troms (18). Dr. Eng hadde bakgrunn både som Gestapo-lege og Quislings livlege og var rekna som ein av dei farlegaste nazistane i Oslo. Heimefronten utførte eit dramatisk og mislykka attentatforsøk mot Eng i heimen hans i krysset Kirkeveien-Suhms gate i Oslo.

Arne Høygaard (1906-81), ein annan prominent NS-lege, blei etter frigjeringa dømd til ei fengselsstraff på eitt år og seks månader (17). Tiltalen omfatta NS-medlemskap, legeteneste for Hirdens flykorps og NS-rekruttar, propagandaartiklar og angiveri. Sidan han ikkje hadde vore ved fronten, blei hans forhold ikkje sett på som så alvorlege. Men i tillegg til fengselsstraffa blei han ekskludert frå Legeforeninga og mista retten til å praktisera for trygdekassa og retten til å bli spesialist. Som tilleggsstraff kom både fagleg og personleg stigmatisering.

Lik mange unge legar var også Høygaard ivrig friluftsmann, som hadde kjørt Spitsbergen på langs med hundeslede, skrive reiseskildring frå Grønland og forsvart doktorgraden på ei avhandling om samanhengen mellom ernæring og fysiopatologi blant folk i arktiske strøk. Etter å ha arbeidd innan ulike fagfelt spesialiserte han seg i pediatri, før han blei helseadministrator under okkupasjonen, mellom anna i Medisinaldirektoratet og Befolkningskontoret, som omfatta befolkningsspørsmål og var sentralt $i$ arbeidet med å utvikle helsestasjonar for mor og barn (19).

Rettsoppgjeret etter frigjeringa tok si tid, og først i 1948 fall dommen over Høygaard. Fri frå varetekt mens han venta på rettargong og dom hadde han mellom anna drive privatpraksis i Oslo. I oktober 1946 klarte politiet å rulla opp eit fluktforsøk og arrestera ein bande landssvikarar på Husø ved Tønsberg. Her dukka lege og matros Arne Høygaard opp i fluktsamanheng for første, men ikkje siste gong (17).

\section{NS-emigrasjonen til Argentina}

Sommaren 1948 var Høygaard sett fri mot meldeplikt. På same tid forlet ei 15 meters redningsskøyte ved namn «Nord» norsk farvatn på veg mot sør. Først fleire månader seinare demrar det for påtalemakta at «Nord» har forsvunne frå riket med NS- prominensar som konsul og «sendemann» Finn Sofus Støren (1893-1962), offiseren Kåre Vagn Knudsen (1905-?) og legen Arne Høygaard om bord (17). Etter krigen hadde konsul Støren vore mykje «sjuk» og ikkje hatt høve til å sona. «Nicht Stören,» som det blei sagt.

I dette selskapet gjennomførte dr. Høygaard ei lang og dramatisk flukt via Portugal, «fransk Nord-Afrika» og Gran Canaria og var framme i Argentina i februar 1949.

\section{«Som i andre euro- peiske land sto tankane om sosialhygiene sterkt også i den norske styringseliten»}

Medan ferda med «Solbris» er den mest kjende, er ferda med «Nord» den mest vellykka NS-flukta frå Norge etter krigen. Den gamle redningsskøyta redda i alle fall Arne Høygaard frå hans livs forlis.

Samla omfatta NS-emigrasjonen til Argentina ein stad mellom 500 og 1000 menneske (17). Berre eit lite fåtal var landssvikdømde flyktningar. Av desse igjen var det ei handfull legar. Stort sett er den norske NS-emigrasjonen til Sør-Amerika ei trist historie, med dårleg tilpassing og ofte heimreise med halen mellom beina. Av fleire grunnar utgjer legane eit unnatak. Dei slo seg ned i Andesfjella, i eit sunt klima dei kjende og beherska. Dei var fagfolk som kunne selja kunnskapane sine, sjølv då arbeidsmarknaden blei trongare og trongare i takt med dei økonomiske vanskane i Argentina i 1950åra. Særleg Arne Høygaard klarte seg godt, han arbeidde som barnelege, gav ut bok om kosthaldet til andinske skuleborn og deltok på internasjonale kongressar som ekspert på ernæring og høgdemedisin. I fritida dyrka den gamle polfararen fjellsport og klatring, blei heidersmedlem $\mathrm{i}$ andinistklubben Fjellets venner og fekk ein fjelltopp i Andes oppkalla etter seg - Cumbre Arne Høygaard. I 1984, tre år etter at han døydde, blei det avduka ein byste over den gamle landssvikar og flyktning framfor sjukestova i Cachi, som i dag ber Arne Høygaards namn.

Dei fleste av desse opplysningane skriv seg frå det arkeologiske museet $\mathrm{i}$ Cachi (20). Utover det har dei emigrerte legane i stor grad levert sterkt retusjerte biografiar om seg sjølve og kvarandre (21). Likevel kan vi slå fast at ved å behandla pasientar som menneske og ikkje samfunnet som pasient, har legar som tok mest feil, gjort opp for seg og sona i medisinsk praksis ved å lindra smerte og liding blant livsdugelege og mindre livsdugelege til liks.

Artikkelen er basert på eit foredrag i Norsk forum for helseledelse, Sundvolden Hotel 11.1. 2014.

\section{Kjartan Fløgstad (f. 1944)}

er forfattar. Temaa i denne artikkelen har han òg skrive om i romanane Grand Manila (2006)

og Grense Jakobselv (2009).

Forfattaren har fylt ut ICMJE-skjemaet og oppgjev ingen interessekonfliktar.

Litteratur

1. Klee E. Das Personenlexicon zum Dritten Reich. Wer war was vor und nach 1945. Frankfurt a. M.: S. Fischer, 2005

2. Hauenstein E. Ärzte im Dritten Reich. Weisse Kittel mit braunen Kragen. Stuttgart: Thieme, 2011

3. Platon. Kriton og Faidon. Ved Anfinn Stigen (1973) Oslo: Samlaget, 1995

4. Nietzsche F. Götzen-Dämmerung oder Wie man mit dem Hammer philosophiert (1889). Berlin: Suhrkamp Verlag, 1984

5. Carey J. Pride \& prejudice among the literary intelligentsia 1880-1939. Chicago, IL: Academy Chicago Publishers, 2002

6. Schmidt U. Karl Brandt: the Nazi doctor. Medicine and power in the Third Reich. London: Hambledon Continuum, 2008

7. Halter H. Die Mörder sind noch unter uns. NSÄrzte: von der Euthanasie zur Massenvernichtung. Der Spiegel 1988; nr. 25.

8. Schiøtz A. Folkets helse - landets styrke, 1850-2003. Oslo: Universitetsforlaget, 2003.

9. Lifton RJ. The Nazi doctors. Medical killing and the psychology of genocide. London: Basic Books, 1986

10. Fløgstad K. Parkens grøde. Om lov og urett i krig og etterkrigstid. Samtiden 2009; nr. 2.

11. d'Almeida F. Med pisk og champagne. Sosietetsliv i Nazi-Tyskland 1933-45. Oslo: Dinamo Forlag. 2006

12. Müller I. Hitler's justice. The courts of the Third Reich. Cambridge, MA: Harvard University Press, 1991

13. Stangneth B. Eichmann vor Jerusalem. Das unbehelligten Leben eines Massenmörders. Zürich-Hamburg: Arche Literatur Verlag, 2011.

14. Nordby T. Karl Evang. En biografi. Oslo: Aschehoug, 1989

15. Bunkholdt V. Hvordan kunne det skje? Tidens oppdragelse - systematisk mishandling eller brodne kar? Tidsskriftet Norges barnevern 2009; nr. 4.

16. Holm I, Kvamme E. De motvillige germanerne. Norske studenter i tysk fangenskap 1943-1945. Oslo: Dreyers forlag, 2013

17. Fløgstad K. Eld og vatn. Nordmenn i Sør-Amerika. Oslo: Universitetsforlaget, 1999

18. Andersen UC. Livlegens besøk. Dagbladet 18.4.2004

19. Gokstad AC. Helse og hakekors: helsetjeneste og helse under okkupasjonsstyret i Norge 1940-1945. Bergen: Alma Mater, 1991.

20. Xamena MA. Dr. Arne Høygaard: Biografía, Museo Arqueológico de Cachí. Manus i brev, Cachí 5.5.1998.

21. Kohn Loncarica AG. La inmigración médica escandinava en la Argentina. Revista Historia 1984: nr. 13: 73-84.

Motteke 28.4. 2014 og godkjent 30.4. 2014. Redaktør: Petter Gjersvik. 